\title{
WANG WEI E O MISTÉRIO DO MUSGO VERDE AZULADO
}

\author{
Antonio José Bezerra de Menezes Jr¹ \\ -Universidade de São Paulo, São Paulo, São Paulo, Brasil \\ Chen Chen 2 \\ ${ }^{2}$ Universidade de Nankai, Tianjin, Tianjin, China
}

Resumo: O poema Lu Zhai (鹿柴; “Parque dos Cervos") do famoso poeta chinês Wang Wei (王維 ; 699-759) é uma de suas obras mais conhecidas e traduzidas no Ocidente. O presente artigo discute e apresenta uma nova interpretação para o verso final do referido poema.

Palavras-chave: Poesia Chinesa; Dinastia Tang; Wang Wei; Lu Zhai

\section{WANG WEI AND THE MISTERY OF THE BLUE-GREEN MOSS}

\begin{abstract}
The poem Lu Zhai (鹿柴; “Deer Park”) by the famous Chinese poet Wang Wei (王維; 699-759) is one of his best known and most translated works in Western world. This article discusses and presents a new interpretation of the final verse of the referred poem.
\end{abstract}

Keywords: Chinese Poetry; Tang Poetry; Wang Wei; Lu Zhai 


\section{王维与“青”苔之谜}

摘要

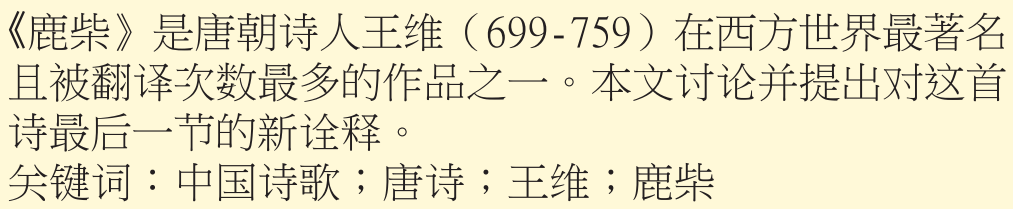

\section{Introdução}

Wang Wei (王維; 699-759) foi um poeta, músico, pintor e estadista chinês que viveu durante a Dinastia Tang (618-906). Ele foi um dos homens mais famosos das artes e letras de sua época. Mais de quatrocentos dos seus poemas são preservados e 29 foram incluídos na famosa antologia do século XVIII conhecida como "Os Trezentos Poemas Tang” (唐詩三百首).

Wang Wei era famoso por sua poesia e suas pinturas, sobre as quais o famoso poeta da Dinastia Song, Su Shi (1037-1101) afirmou: "A qualidade dos poemas de Wang Wei está na pintura que existe dentro deles. Ao observar suas pinturas, pode-se perceber que ali também existe poesia”.

Cerca de quatrocentos de seus poemas sobreviveram graças ao esforço feito pelo seu irmão mais novo, Wang Jin, a pedido do imperiador. Além disso, várias das suas criações mais famosas, como o poema Lu Zhai (鹿柴; “Parque dos Cervos”), integram uma coletânea intitulada “Wangchuan ji” (辋川集), escrita por Wang Wei e o seu amigo Pei Di. Os poemas dessa coleção, inspirados nas paisagens próximas ao santuário de Lantian, são aparentemente simples, no entanto resultam de observações profundas sobre as paisagens e a vida humana segundo os ensinamentos budistas. Tais características levaram Wang Wei a ser conhecido como o "poeta pintor" e como o "Buda dos poetas". 


\section{Dezenove visões de Wang Wei mais três}

Algo semelhante ao "samba de uma nota só", conhecida canção brasileira de Tom Jobim e Newton Mendonça, Eliot Weinberger e Octavio Paz publicaram em 1987 uma antologia de traduções de um único poema de WangWei, justamente o poema Lu Zhai.

A obra intitulada 19 Ways of Looking at Wang Wei contém dezessete traduções para o inglês e duas para o espanhol, todas elas comentadas por Weinberger e Paz. A este repertório especializado, podemos acrescentar três traduções para o português feitas no Brasil em anos recentes.

A primeira pertence ao poeta Haroldo de Campos (1929-2003), publicada originalmente em 1988 num artigo com o sugestivo título "Três Versões do Impossível" (Folhetim num. 583 do jornal Folha de São Paulo de 08/04/1988) e posteriormente incluída na antologia "Escrito sobre Jade" de 2009.

\section{O Refúgio dos Cervos}

$\begin{array}{ll}\text { montanha vazia } & \text { não se vê ninguém } \\ \text { ouvir só se ouve } & \text { um alguém de ecos } \\ \text { raios do poente } & \text { filtram na espessura } \\ \text { um reflexo ainda } & \text { luz no musgo verde }\end{array}$

(Campos 51)

A segunda pertence aos tradutores Sergio Caparelli e Sun Yuqi, publicada na obra Poemas clássicos chineses: Li Bai, Du Fu e Wang Wei de 2012 


\section{O Parque dos Cervos}

Montanha deserta.

Ninguém à vista.

Só eco de vozes.

A luz do poente

entre ramagens.

Sobre o musgo,

um fulgor: verde.

(Caparelli e Sun 209)

A terceira pertence aos tradutores Ricardo Primo Portugal e Tan Xian, publicada na obra Antologia da poesia clássica chinesa - dinastia Tang de 2013

\section{O retiro dos cervos}

vazia a montanha ninguém se vê entanto rumores vozes se ouvem torna a luz poente até o bosque denso ainda ilumina o musgo verde sobre (Portugal e Tan 144)

Todas estas excelentes traduções estão em consonância com o conceito de reimaginação (Faleiros 37-39) e seguem pari passu o texto original do poema apresentado a seguir: 
Tabela 1: Traduções

\begin{tabular}{|c|c|c|c|c|}
\hline 鹿lu4 & 柴zhai4 & & & \\
\hline $\begin{array}{l}\text { veado, poder } \\
\text { político, celeiro, } \\
\text { sobrenome }\end{array}$ & $\begin{array}{l}\text { chai2: lenha, } \\
\text { madeira } \\
\text { zhai4: cerca, } \\
\text { capa, cerca de } \\
\text { defesa, vila }\end{array}$ & & & \\
\hline 空kong1 & 山shan1 & 不bu2 & 见jian4 & 人ren2 \\
\hline $\begin{array}{l}\text { vazio, vazio, } \\
\text { vazio, deserto, } \\
\text { aberto, espaçoso, } \\
\text { silencioso, } \\
\text { imóvel, fictício, } \\
\text { fabricado }\end{array}$ & $\begin{array}{l}\text { montanha, colina, } \\
\text { pico }\end{array}$ & $\begin{array}{l}\text { não, nem } \\
\text {... nem..., } \\
\text { sem, não há } \\
\text { necessidade }\end{array}$ & $\begin{array}{l}\text { ver, avistar, } \\
\text { observar, } \\
\text { perceber, } \\
\text { conhecer }\end{array}$ & $\begin{array}{l}\text { cara, pessoas, } \\
\text { humanidade, } \\
\text { alguém, } \\
\text { pessoas } \\
\text { comuns }\end{array}$ \\
\hline 但dan4 & 闻wen2 & 人ren2 & 语yu3 & 响xiang3 \\
\hline $\begin{array}{l}\text { apenas, mas, no } \\
\text { entanto, ainda } \\
\text { assim, sentir } \\
\text { livre, desde que }\end{array}$ & $\begin{array}{l}\text { ouvir, cheirar, } \\
\text { fazer a conhecer, } \\
\text { ser informado, } \\
\text { saber, bem } \\
\text { conhecido }\end{array}$ & $\begin{array}{l}\text { cara, } \\
\text { pessoas, } \\
\text { humanidade, } \\
\text { alguém, } \\
\text { pessoas } \\
\text { comuns }\end{array}$ & $\begin{array}{l}\text { linguagem, } \\
\text { palavras, } \\
\text { dizer, } \\
\text { expressão, } \\
\text { discutir, } \\
\text { conversar, } \\
\text { discutir, } \\
\text { debater }\end{array}$ & $\begin{array}{l}\text { fazer o som, } \\
\text { fazer barulho, } \\
\text { som, eco, } \\
\text { mensagem, } \\
\text { barulhento }\end{array}$ \\
\hline 返fan3 & 景jing3 & 人ru4 & 深shen1 & 林lin2 \\
\hline $\begin{array}{l}\text { retornar, reverter } \\
\text { para, restaurar, } \\
\text { alterar }\end{array}$ & $\begin{array}{l}\text { cenário, vista, } \\
\text { condições, } \\
\text { luz solar, sol, } \\
\text { tempo, admirar, } \\
\text { respeitar, } \\
\text { sortudo, alto }\end{array}$ & $\begin{array}{l}\text { entrar, entrar } \\
\text { (para), } \\
\text { participar, } \\
\text { ser admitido, } \\
\text { tornar-se } \\
\text { membro, }\end{array}$ & $\begin{array}{l}\text { profundo, } \\
\text { distante; } \\
\text { muito, } \\
\text { extremo, } \\
\text { profundo, } \\
\text { penetrante, }\end{array}$ & $\begin{array}{l}\text { floresta, } \\
\text { bosque, } \\
\text { bosques, } \\
\text { sobrenome, } \\
\text { local isolado, } \\
\text { círculo, }\end{array}$ \\
\hline
\end{tabular}




\begin{tabular}{|l|l|l|l|l|}
\hline & & $\begin{array}{l}\text { pagar, } \\
\text { conformar- } \\
\text { se, atingir } \\
\text { grave, } \\
\text { extremamente } \\
\text { sério }\end{array}$ & $\begin{array}{l}\text { duro, muito } \\
\text { vários }\end{array}$ & $\begin{array}{l}\text { subio, } \\
\text { 复fu4 }\end{array}$ \\
\hline $\begin{array}{l}\text { retornar, repetir, } \\
\text { repetidamente, } \\
\text { restaurar, } \\
\text { responder, } \\
\text { retaliar, executar, } \\
\text { remeter, retomar } \\
\text { brilhar, refletir, } \\
\text { brilhante, } \\
\text { iluminar, cuidar, } \\
\text { entender, tirar } \\
\text { (uma foto), luz } \\
\text { solar, fotografia, } \\
\text { licença, de } \\
\text { acordo com }\end{array}$ & verde, azul, \\
preto, jovem & musgo, líquen & $\begin{array}{l}\text { 青qing1 } \\
\text { superior, } \\
\text { subir, enviar } \\
\text { para cima, } \\
\text { alto, céu, } \\
\text { superiores, } \\
\text { autoridade, } \\
\text { imperador, } \\
\text { primeira } \\
\text { classe, } \\
\text { anterior, } \\
\text { distante }\end{array}$ \\
\hline
\end{tabular}

Fontes: Os autores

\section{Os problemas de um problema}

A obra de Weinberger e Paz nos remete ainda ao notável conto "Pierre Menard, autor do Quixote", de Jorge Luis Borges (18991986). No referido texto, o escritor argentino lista a diversificada e extravagante produção intelectual de Pierre Menard, dentre as quais destacamos:

m) A obra Les Problèmes d'un Problème (Paris, 1917) que discute em ordem cronológica as soluções do ilustre problema de Aquiles e a tartaruga. Duas edições desse livro apareceram até agora; a segunda traz como epígrafe o conselho de Leibniz 'Ne craignez point, monsieur, la tortue', 
e renova os capítulos dedicados a Russell e a Descartes. (Borges 49)

Ou seja, diante do problema de traduzir o famoso poema "Lu Zhai" de Wang Wei, Weinberger e Paz apresentam também diversas soluções que por sua vez geram novos problemas quando confrontados com o texto original, trazendo sempre de volta o espectro da intraduzibilidade da poesia chinesa (Jatobá 216-218).

Contudo, o ponto que nos interessa neste breve estudo é o mistério do musgo cuja descoberta é o ponto focal do poema e, sobretudo, a sua instigante cor verde azulada.

\section{O musgo é um musgo é um musgo}

Parafraseando Gertrude Stein ("Rose is a rose is a rose is a rose") o musgo representa a forma inesperada e desconcertante com que o zen se apresenta quando confrontado de maneira intelectualista ou quando interpelado por uma curiosidade frívola. Desta forma, o poema funciona também como as famosas anedotas dos mestres zen (公案 gong1 an4, em japonês koan) tal como esta do mestre zen japonês Kakua:

Quando Kakua voltou ao Japão depois de estudar vários anos na China, o Imperador, que ouvira dizer que ele aprendera uma nova doutrina, mandou chamá-lo à sua presença para interrogá-lo sobre ela.

Quando o Imperador lhe perguntou o que era o Zen, Kakua fez uma profunda reverência, tirou das dobras de seu quimono uma flautinha, soprou uma nota, guardou o instrumento, fez nova reverência e desapareceu. Nunca mais ninguém ouviu falar nêle. (Gonçalves 205) 
Qual seria o significado dessa nota musical de Kakua? Essa pergunta que ecoa na mente do discípulo, exige um desprendimento e uma intuição mais profunda.

No caso do poema "Lu Zhai", Wang Wei vai além de apenas deixar consignada a pergunta característica do zen sobre o significado do musgo ao escolher uma tonalidade particularmente indefinida e especial para identificá-lo.

Conforme vimos anteriormente, a palavra 青 (qing1) significa "verde, azul, preto, jovem". Ao invés de escolher uma cor específica como “verde” (绿 lü4) ou “azul” (蓝 lan2), o poeta opta por uma tonalidade cujo espectro vai do azul ao verde incluindo o preto. Tal escolha não é casual pois, como observa o escritor e erudito chinês Lin Yutang (1895-1976), os poetas da Dinastia Tang são extremamente cuidadosos quanto ao vocabulário utilizado:

A diferença entre a poesia T'ang e o "Livro da Poesia" [Shi Jing] é a diferença entre um galho de flores cuidadosamente arranjado num vaso, onde cada ângulo e cada curva é estudada carinhosamente, e o desenvolvimento luxuriante de um jardim silvestre. Esses poemas [do Shi Jing] representam para nós a voz do povo antigo, fresca, direta e sem afetação, e algumas vezes despudorada. Num namoro ouvese a voz dos namorados, o que é impossível nos poemas dos letrados T'ang. Ouvimos também uma surpreendente variedade de temas, de fugas, os anseios de donzela, a esposa abandonada, a mulher divorciada, a luxúria dos ricos, a caça, guerras, soldados em serviço e sátiras contra as classes abastadas. (Lin 322)

Vale observar ainda que existe de fato uma planta originária da China e do Camboja chamada Selaginella willdenowii também conhecida popularmente como "Musgo-Azul". Trata-se de uma espécie aparentada das samambaias e que possui propriedades iridescentes, ou seja, a sua cor varia conforme o ângulo de incidência da luz, indo do verde ao azul. 
Figura 1: Selaginella willdenowii

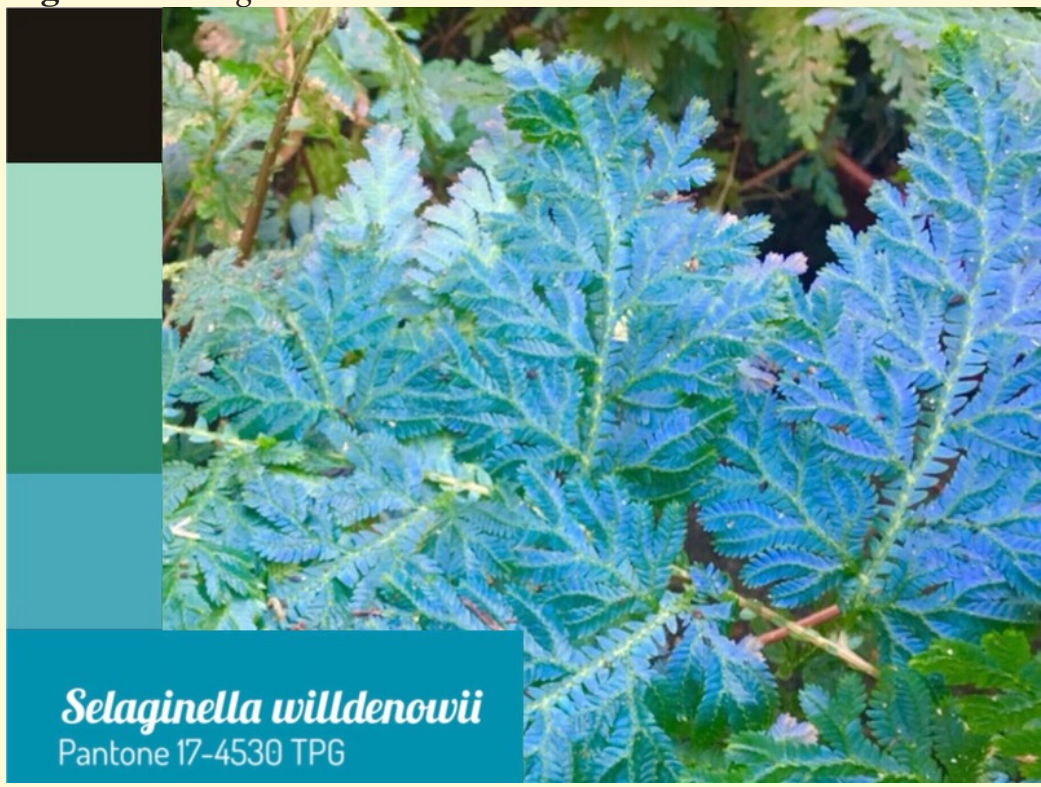

Fonte: Carol Costa, site "Minhas Plantas"1

Não se pode afirmar que o poeta tenha se referido a esta planta em particular, contudo o uso da palavra 青 (qing1) poderia ser um índice desse incomum e exuberante dinamismo cromático.

\section{Da capo (de volta ao início)}

O escritor Graham Greene (1904-1991) quando questionado sobre a relação entre sua confissão religiosa e sua atividade literária, dizia ser ele apenas "um católico que escreve" enquanto que Evelyn Waugh (1903-1966) seria de fato "um escritor católico".

${ }^{1}$ https://minhasplantas.com.br/plantas/musgo-azul/imagem/762/ 
Da mesma forma, a tonalidade verde azulada faz com que em Wang Wei o poeta pintor prevaleça sobre o poeta budista ou antes sobre o budista que escreve poemas. Em outras palavras (e acrescentando novas dificuldades para os tradutores de poesia chinesa) toda a riqueza e complexidade pictórica do poeta não devem ser ofuscadas pela iluminação zen, de tal modo que o poema não deixe no leitor a impressão final de um lacônico musgo, mas sim de um extraordinário jardim verde azulado.

\section{Referências}

Borges, Jorge Luis. Ficções. São Paulo: Editora Abril, 1972.

Campos, Haroldo de. Escrito sobre Jade. São Paulo: Ateliê Editorial, 2009, 2a edição revista e ampliada. Org. Trajano Vieira.

Caparelli, Sergio e Sun, Yuqi. Poemas clássicos chineses: Li Bai, Du Fu e Wang Wei. Porto Alegre: L\&PM, 2012.

Faleiros, Álvaro. "Na esfera da reimaginação". Cadernos de Literatura em Tradução, São Paulo, no 11 (2010): 37-46. Disponível em: http://www.revistas. usp.br/clt/article/view/49484. Acesso em: 31. set. 2019

Gonçalves, Ricardo Mário. Textos Budistas e Zen-Budistas. São Paulo: Editora Cultrix, 1967.

Jatobá, Júlio Reis. "Poesia e (in)traduzibilidade na língua chinesa". Scientia Traductionis, Florianópolis, $\mathrm{n}^{\mathrm{o}} 13$ (2013): 213-223. Disponível em: https:// periodicos.ufsc.br/index.php/scientia/article/view/30271. Acesso em: 31. set. 2019

Lin, Yutang. A Sabedoria da Índia e da China. São Paulo: Irmãos Pongetti, 1942. 
Portugal, Ricardo Primo e Tan, Xian. Antologia da poesia clássica chinesa dinastia Tang. São Paulo: Editora da Unesp, 2013.

Weinberger, Eliot e Paz, Octavio. 19 Ways of Looking at Wang Wei. Kingston, Rhode Island: Asphodel Press, 1987.

Recebido em: 09/10/2019

Aceito em: 30/11/2019

Publicado em dezembro de 2019

Antonio José Bezerra de Menezes Jr. E-mail: antonio.menezes@usp.br ORCID: https://orcid.org/0000-0001-7782-9261

Chen Chen. E-mail: flavia.chenchen@gmail.com

ORCID: https://orcid.org/0000-0003-2844-4490 